OPEN ACCESS

Edited by: Stevo Popovic, University of Montenegro, Montenegro

Reviewed by:

Bojan Masanovic, University of Montenegro, Montenegro Mustafa Sögüt, Middle East Technical University, Turkey

${ }^{*}$ Correspondence: Massimo Lanza massimo.lanza@univr.it

tThese authors have contributed equally to this work and share first authorship

Specialty section: This article was submitted to Children and Health a section of the journal Frontiers in Pediatrics

Received: 29 September 2021 Accepted: 08 November 2021 Published: 10 December 2021

Citation:

Giuriato $M$, Biino V, Bellafiore $M$ Battaglia G, Palma A, Baldari C, Guidetti L, Gallotta MC, Schena F and

Lanza M (2021) Gross Motor Coordination: We Have a Problem! A Study With the Körperkoordinations Test für Kinder in Youth (6-13 Years). Front. Pediatr. 9:785990.

doi: 10.3389/fped.2021.785990

\section{Gross Motor Coordination: We Have a Problem! A Study With the Körperkoordinations Test für Kinder in Youth (6-13 Years)}

\author{
Matteo Giuriato ${ }^{1,2 t}$, Valentina Biino ${ }^{1,3+}$, Marianna Bellafiore ${ }^{4}$, Giuseppe Battaglia ${ }^{4}$, \\ Antonio Palma ${ }^{4}$, Carlo Baldari ${ }^{5}$, Laura Guidetti ${ }^{6}$, Maria Chiara Gallotta ${ }^{7}$, \\ Federico Schena ${ }^{8}$ and Massimo Lanza ${ }^{8 *}$
}

${ }^{1}$ Department of Human Sciences, University of Verona, Verona, Italy, ${ }^{2}$ Unit of Molecular Biology, Department of Health and Natural Sciences, Faculty of Physical Culture, University of Physical Education and Sport, Gdansk, Poland, ${ }^{3}$ School University of Medicine and Surgery, University of Verona, Verona, Italy, ${ }^{4}$ Sport and Exercise Sciences Research Unit, University of Palermo, Palermo, Italy, ${ }^{5}$ Department of Theoretical and Applied Sciences, eCampus University, Novedrate, Italy, ${ }^{6}$ Department of Unicusano, University Niccolò Cusano, Rome, Italy, ${ }^{7}$ Department of Physiology and Pharmacology "Vittorio Erspamer", Sapienza University of Rome, Rome, Italy, ${ }^{8}$ Department of Neurosciences, Biomedicine and Movement Sciences, University of Verona, Verona, Italy

The main goal of our cross-sectional research was to determine the current values of gross motor coordination (GMC) of Italian boys and girls between 6 and 13 years of age. Secondary goals were to study gender differences, and the four subtests trend with ages. Results were compared with the references proposed by KTK authors and with similar searches. Anthropometric measurements and KTK data from 2,206 schoolchildren (girls: $n=1,050$; boys: $n=1,156)$ were collected. The KTK raw score (RS) increased with the age of the subjects $(r=0.678 ; p<0.001)$. In 11-13-year-old subjects, the increase in results is less than in younger subjects. RS showed differences by gender ( $F=5.899$; $p=0.015)$ and age $(F=269.193 ; p<0.001)$ without interaction gender $\times$ age. Motor quotient $(\mathrm{MQ})$ tended to decrease with age $(r=-0.148 ; p<0.001)$; it showed differences by gender $(F=79.228 ; p<0.001)$, age $(F=14.217 ; p<0.001)$, and an interaction gender $\times$ age $(F=2.249 ; p<0.05)$. Boys showed better performance than did girls in the raw scores of three of four subtests (JS: $F=24.529$; MS: $F=9.052 ; \mathrm{HH}: F=11.105$ ). Girls show better performances than did boys in the WB ( $F=14.52)$. Differences between genders make us believe it appropriate to maintain a differentiated standardization. RS increased with age, and it seems reasonable, therefore, to maintain a GMC age-based normalization. On the contrary, $\mathrm{MQ}$ tended to decrease. All this makes us speculate that today's young people accumulate less significant motor experiences over the years compared to those achieved by their peers in the 1970s. Italian data were lower than German references and Belgian results but slightly higher than the Brazilian ones. The comparison among these four searches confirmed a worrying downward trend in GMC and its characterization by geographical and sociocultural areas. Updated parameters of the KTK can provide helpful references to improve policies to support physical activity, sport, and physical education in youth.

Keywords: gross motor coordination, KTK, youth development, children, physical activity, health, motor coordination (MC) 


\section{INTRODUCTION}

Motor learning and control characterize children development and their adaptation to the physical and social environment. The manifestation of motor learning and control is the children's motor competence. It can be defined as mastery in fundamental movement skills (e.g., walking, throwing, and catching) and in more specialized movement sequences such as lifelong physical activity abilities like cycling, swimming, or sport-specific skills (1). Motor abilities are articulated in basic stability (static or dynamic balance), manipulation, object control, and locomotor abilities (2). Basic stability and locomotor abilities, often defined as "gross motor coordination" (GMC), involve the control of two or more body segments and/or the global movement of the body in space (3). These two aspects of movement are fundamental both in the acquisition of fundamental motor skills (FMS) and in the development of specialized movements and techniques of daily life and sport. FMS is generally categorized into basic locomotor skills that lead children to transfer the body in space (e.g., walking and running) and object control skills that allow them to manipulate and project objects (i.e., striking, kicking, etc.) (4). In both cases, both the stability and the coordination of the body segments are necessary for a mastery of the movements (2).

The GMC is essential for acquiring both advanced control of FMS and that of specialized movement techniques. Consequently, it is also necessary for the training of healthrelated physical abilities, such as strength, endurance, and flexibility, and for those related to sports performance. GMC provide the basis to reaching a high level of motor competence (MC), to develop adequately, maintain health, and gain athletic excellence (5). GMC, therefore, plays a crucial role in the development and active lifestyle (6). Children with a high level of coordination are more involved in physical activity (PA) and sport and tend to reach better performance $(7,8)$. On the other hand, children with a low level of coordination are less inclined to participate in physical activities (9-11). Numerous studies confirm the relationship between low motor skill levels in children, poor PA, and increased BMI during developmental age (12-14), especially in girls (15). Physical inactivity leads to a worsening of body weight and fat mass with a negative influence on GMC tasks $(15,16)$. Data from Lopes et al. (17) showed that clumsy children have higher BMI levels more frequently. The term GMC, in this paper, will be used to refer to the ability to execute a wide range of motor activities involving whole-body movement $(3,18)$.

GMC in childhood influences, directly and indirectly, healthrelated physical fitness and the development of long-term health outcomes in children and adolescents (19). Several researchers (11, 20-23) studied the coordination role in promoting health, yet it is still an open question. Poor GMC prevents children from reaching a good level of motor skills (24) and, consequently, does not allow them to participate safely and vigorously in sports practices (10). On the contrary, mastering motor skills in childhood seems to help children participate regularly in organized sports and spontaneous physical activities $(12,15,25-28)$.
In the vast domain of exercise for health, the relationship between motor coordination and cognitive development also begins to show significant evidence $(29,30)$. Findings support the association between motor coordination and executive function in childhood $(31,32)$, adolescence (33) and in all other phases of life (34). Marchetti et al. (35) suggests that the cognitive demands of complex movement and sport tasks, as well as sensorimotor learning, may be responsible for the positive association of PA and sports with higher-level cognition and metacognition.

Despite this mass of evidence that assigns coordination a significant role in movement education and health promotion, there are some serious obstacles to study and structurally promote this aspect of motor skills. Assessing GMC is complex because it manifests itself in countless modes of movement: locomotion, object control, postural stability, and dynamic balance. Stability represents the most basic of the movement and sport. For this reason, stability begins to develop early in life and often children who are exposed to a variety of movement experiences have no difficulty developing fundamental stability abilities (2). Several literature reviews (1,36-39) identify a second obstacle in the coordination study: the lack of a reference test shared by the entire scientific community. Several tests' batteries have been proposed and validated, some with the specific purpose of identifying subjects with coordination difficulties, others for measuring different aspects of coordination, others still applicable to FMS. Among these batteries, we find significant differences related to the type of movements investigated and the age groups in which they can be applied. Only some batteries provide standard values for girls and boys (36). All this results in the lack of a "Gold standard" to assess coordination. It is relevant to overcome these difficulties also from an educational perspective to promote motor literacy in young people. Indeed, PA guidelines for youth (40-44) indicate the necessity to develop a large patrimony of motor skills and a positive attitude toward motor learning. These goals, however, cannot be properly pursued and documented in the absence of a shared way to measure them. Lastly, since the assessment of GMC at a young age must be applied to a large number of people, such as in physical education classes and sports training, the assessment tools need the characteristics of applicability and simplicity of execution (36). Vandorpe et al. (45) suggested that GMC cannot be assessed independently from the pure fitness characteristics (e.g., strength, speed, endurance, and flexibility). Further, in terms of health, the physical components in relation to GMC have been evaluated extensively (45). The Körperkoordinations Test für Kinder (Body Coordination Test for Children) $(46,47)$ seems to be one of the batteries that can meet the requirements described above (48). It was conceived and validated, with a population of 1,228 German subjects between 5 and 14 years of age by Kiphard and Schilling in 1974 (46) and verified in 2007. The four subtests make it up to measure different aspects of the GMC, not related to specific sports skills (3). Gross motor coordination is always measured in association with some of the physical abilities such as strength, speed, endurance, and flexibility (45). Most test batteries consist of elements that measure both physical and coordination skills (49). KTK also measures GMC in movements that also involve strength and 
speed characteristics $(46,47)$. The four subtests are "Walking backwards" (WB), "Jumping sideways" (JS), "Moving sideways" (MS), and "Hopping for height" (HH). The four subtests are used, with the same parameters, in all ages of test application, allowing, and so also longitudinal studies. The test takes about 20 min per child. The KTK is a battery suitable in different fields like physical education, sports, health promotion (48), and talent identification (50).

Some limitations of the KTK are the lack of indications for the control of objects, the tendency to overestimate the number of children with GMC problems, and the comparison with standardized values based on data from 1974 that may be obsolete (48). This last point can, however, be considered also a positive element because it allows the study of GMC's change over long periods.

GMC plays a critical role in youth development and active lifestyle, but these parameters are, however, lacking, particularly in Italy where, to our knowledge, only surveys have been carried out on small groups $(51-55)$ or in pre-school age $(56,57)$.

The main goal of our cross-sectional research was to verify for the first time the current values of GMC of Italian boys and girls between 6 and 13 years of age based on a large cohort of Italian children. Our results were compared with the values proposed by Kiphard and Schilling (46) and with similar researches that used the KTK in more recent years $(45,58)$. Based on our previous unpublished studies as well as Vandorpe et al. (45) and Moreira et al. (58) data, it was assumed that the current coordination levels of Italian boys and girls are lower than the reference values of the KTK battery. Secondary goals were to study gender differences, and the four subtests trend with ages. In all four subtests, we assume an increase in raw values that slowed down with increasing age. We expected that girls exhibit similar or higher values than boys in the WB. In the JS and $\mathrm{HH}$, boys should show overall values higher than those of girls due to higher strength levels. There are no known reasons to assume gender difference in MS.

\section{METHODS}

\section{Participants}

Two thousand two hundred six schoolchildren (girls: $n=1,050$; boys: $n=1,156$ ), aged between 6 and 13 years (Table 1), from 49 primary and lower secondary schools (private and public), representative of the Italian geographical areas (North Italy $=$ Veneto; Center Italy = Lazio; South Italy = Sicily) were randomly recruited in this cross-sectional study (convenient sample), including urban and rural areas. The included schools were equipped with appropriate and similar sports facilities to conduct comparable measurements. Sample procedures considered the total number of schools (private and public), geographic regions (north, center, south), and urban and rural places. The population examined is similar to or greater than that of similar studies (45-51). The measurements were conducted from January 2019 to February 2020. The Ethical Boards of the Universities of Verona (N. 2019-UNVRCLE-0298910) and Palermo (N. 8/2019) as well as the Institutional Review Board of the University of Rome "Foro Italico" approved the study.
The study complies with the criteria for the use of people in research defined in the Declaration of Helsinki. Moreover, school principals provided further research authorizations. After researchers explained the purpose of the investigation and the research methodology, all parents provided written informed consent before participating in the study. All the measures were taken during the Physical Education lessons as scheduled in the morning framework (8.00-12.00 a.m.). All assessments were carried out by trained supervisors (Physical Education teachers or specifically trained Sport Science's students) in the same gym school context. The presence and collaboration of the curricular PE teachers were guaranteed at any time to meet the confidence of the students. The trainer-pupil ratio was 1:10.

\section{Anthropometric Measurements}

To ensure that the subjects correctly represented the Italian population with regard to the proportion of underweight, normal weight, overweight, and obese subjects, weight and height measurements were collected. Anthropometric measurements were taken according to the standard procedures described by the International Society for the Advancement of Kinanthropometry (59). Height was measured with a stadiometer to the nearest $0.5 \mathrm{~cm}$. Weight was measured to the nearest $0.1 \mathrm{~kg}$ with an electronic scale with the subject wearing minimal clothing. Children were classified as underweight, normal weight, overweight, and obese using age- and gender-specific cutoff points $(60,61)$.

\section{Gross Motor Coordination Measurements}

GMC was evaluated through Körperkoordinations Test für Kinder, referred to as KTK $(46,47)$, which consisted of four items:

1. Walking backwards-WB: walking backwards three times along each of three balance beams ( $3 \mathrm{~m}$ length; $6,4.5$, and $3 \mathrm{~cm}$ width, respectively; $5 \mathrm{~cm}$ height). A maximum of 24 steps (eight per trial) was counted for each balance beam, which comprises a maximum of 72 steps ( 24 steps $\times 3$ beams) for this test.

2. Jumping sideways-JS: jumping laterally as many times as possible over a wooden slat $(60,4$, and $2 \mathrm{~cm})$ in $15 \mathrm{~s}$. The number of jumps over two trials was summed.

3. Moving sideways-MS: moving across the floor in $20 \mathrm{~s}$ by stepping from one plate $(25 \times 25 \times 5.7 \mathrm{~cm})$ to the next, transferring the first plate, stepping on it, etc. The number of relocations was counted and summed over two trials.

4. Hopping for height-HH: jumping from one leg over an increasing pile of pillows $(60 \times 20 \times 5 \mathrm{~cm}$ each $)$ after a short run-up. Three, two, or one point(s) were/was awarded for successful performance on the first, second, or third trial, respectively. A maximum of 39 points (ground level plus 12 pillows) could be scored for each leg, yielding a possible maximum score of 78 .

KTK test and its scoring were carried out according to the authors' indications $(46,47)$. Children were tested alone or in small groups, and the tasks were performed one child at a time, during the physical education lessons, in the school gymnasium. 
TABLE 1 | Number of subjects, mean values of raw score (RS), and motor quotient (MQ) by gender and age.

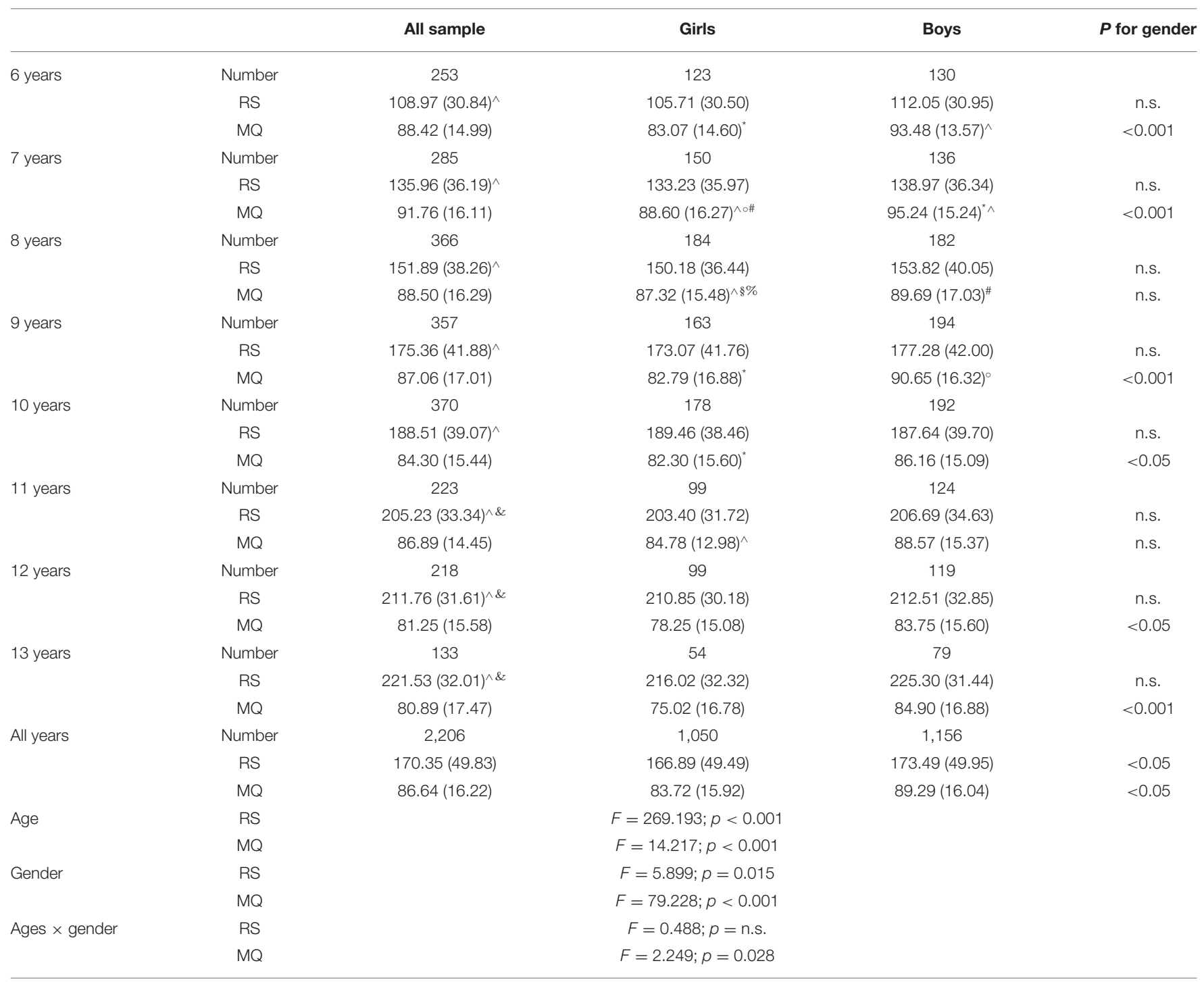

All sample: ${ }^{\wedge} p<0.001$ between all couples, ${ }^{\&} p=$ n.s. 13 vs. 12 and 12 vs. 11.

Girls: ${ }^{*} p<0.01$ vs. 13 years, ${ }^{\wedge} p<0.001$ vs. 13 years, ${ }^{\circ} p<0.01$ vs. 9 years, ${ }^{\#} p<0.01$ vs. 10 and 12 years, ${ }^{\S} p<0.01$ vs. 10 years, ${ }^{\circ} p<0.001$ vs. 12.

Boys: ${ }^{*} p<0.01$ vs. 8 and 11 years, ${ }^{\wedge} p<0.001$ vs. 10,12 , and 13 years, ${ }^{\circ} p<0.001$ vs. 12 years, ${ }^{\#} p<0.01$ vs. 12 years.

Before each test, the children received an oral explanation about the procedure. For the raw score on the total test battery, a test-retest reliability coefficient of 0.97 was reported. For the four subtests, based on the raw score, sufficiently reliable coefficients were reported as well (WB: 0.80; MS: 0.84; $\mathrm{HH}$ : 0.96; JS: 0.95). Intercorrelations between the four subtests varied from $0.60(\mathrm{WB} / \mathrm{JS})$ to $0.81(\mathrm{HH} / \mathrm{JS})$ for the reference group of 1,228 children. Factor analysis revealed that the four subtests all load on the same factor, namely, GMC. The percentage of total variance of the KTK explained by the four subtests varied from 80.9 (age 6) to 97.7 (age 9) $(46,47$ ). The KTK allows an objective and straightforward evaluation of a child's gross motor coordination only, with only limited interference of the child's physical fitness, which discriminates this test from most other instruments. The raw test scores from each of the four subtests can be transformed into gender- and age-specific motor quotients value (MQ), which were based on the performance of 1,228 normally developing German children in 1974. Scoring of the KTK test was performed according to the manual (47). The mean standardized value is 100 with a standard deviation of $15(46,47)$. MQ describes the level of $\operatorname{GMC}(45,47)$, and values between 85 and 115 describe the normality (Table 6).

The measurements obtained from the KTK are the following:

- The raw results of the four tests that make up the KTK (WB raw, MS raw, JS raw, and $\mathrm{HH}$ raw);

- The sum of the four subtests raw values called "Raw score" (RS);

- The four normalized values of the subtests (WB, MS, JS, and $\mathrm{HH}$ ), obtained from the normalization tables for age and 
gender $(41,42)$. The mean of each of the four standardized values is 100 with a standard deviation of 15 ;

- The sum of the four standardized values (MQ raw);

- The "Motor Quotient" (MQ), obtained from the standardization tables. It summarizes the overall normalized value of gross motor coordination measured with the KTK.

In our research, we considered all the above measures except the sum of the standardized values of the four tests, which are largely represented by MQ.

\section{Statistical Analysis}

The Shapiro-Wilk-test for normality was initially used to evaluate the distribution of data. Number frequency was displayed to describe age and gender classes. The chi-square test was carried out to study any significance between frequencies of gender according to age groups. The scores of the KTK were calculated and showed as means and SDs by age and gender. A Spearman correlation was used for not normally distributed data and Pearson correlation for normally distributed data. The two-way ANOVA was run to examine if there was an interaction effect between the independent variables age and gender on all KTK scores. The comparison between the results of the various researches was carried out with one-way ANOVA using the values of the means, the number of subjects, and the standard deviations. The results of ANOVA were displayed through the F-values; significant interaction and main effects were examined with Bonferroni post-hoc tests. Level of significance was set at $p<0.05$. The software SigmaStat for Window, version 3.5 (Systat Software Inc., Erkrath, Germany), was used to perform the statistical analyses.

\section{RESULTS}

\section{RS and MQ Analyses}

Table 1 illustrates the characteristics of the subjects involved in the study that presents a homogeneous distribution by age and gender. It was also verified that the prevalence of underweight, normal-weight, overweight, and obese children was consistent with recent data on Italian children of the same age (62). In particular, the four BMI categories presented the following percentages: underweight $=8 \%$, normal weight $=61 \%$, overweight $=22 \%$, obese $=9 \%$. Table 2 describes the mean values of all KTK parameters and their correlations with the age of the subjects.
RS increased with the age of the subjects $(r=0.678 ; p<0.001)$ progressively reducing, however, the increase. Up to 11 years, the annual differences are always significant, while subsequently, it is between 11 and 13 years. RS shows differences by gender ( $F$ $=5.899 ; p=0.015)$ and age $(F=269.193 ; p<0.001)$ without interaction gender $\times$ age $(F=0.48 ; p=$ n.s. $)$. Overall, boys show higher RS values than girls (girls $=166.89 \pm 49.49$; boys $=173.49$ $\pm 49.95 ; F=5.899 ; p<0.05$ ), but the gender comparison for each age group does not show significant differences in any of the eight pairs (Table 1).

MQ tends to decrease with age $(r=-0.148 ; p<0.001)$ and shows differences by gender $(F=79.228 ; p<0.001)$, age $(F=$ 14.217; $p<0.001)$, and an interaction gender $\times$ age $(F=2.249$; $p<0.05)$. Among the girls, 13 -year-olds show a lower mean $(p$ $<0.01 \div 0.001)$ than all the others except for the 12 -year-olds; 7 -year-old girls have better values than 9 -13-year-olds $(p<0.01$ $\div 0.001)$; and 8 -years-olds have better values than 10 -year-olds $(p<0.01)$. Seven-year-old boys have better values than 8 -, $10-$ 13-year-olds $(p<0.01 \div 0.001)$; 6-year-olds have better values than 10-, 12-, 13-year-olds ( $p<0.001)$; and 12-year-olds show a lower mean $(p<0.01 \div 0.001) 6-9$-year-olds. In the analysis by age groups, boys always show higher values than girls except at 8 and 11 years.

\section{Analysis of the Four Subtests: WB, MS, JS, and $\mathrm{HH}$}

Tables 3, 4 show, respectively, the raw score and standardized values of the four KTK subtests for gender and age. In the raw values of the four subtests, significant differences $(p<0.001 \div 0.01)$ by gender and age emerged without interaction gender $\times$ age. In standardized values of all subtests, significant differences $(p<0.001)$ by gender and age were found, with interactions gender $\times$ age in JS $(p<01)$ and $\mathrm{HH}(p<0.001)$.

In WB raw, girls perform better than boys $(F=14.52$; $p<0.001)$. Globally, WB raw increased with age $(r=$ $0.459 ; p<0.001)$. In the post-hoc analysis by age group, significant differences for all but five age groups were found: 6 vs. 7 years, 9 vs. 10 years, 11 vs. 12 years, and 13, 12 vs. 13 years (Figure 1A). The standardized mean value of $\mathrm{WB}$ is lower than the reference (respectively, $88.33 \pm 17.27$ vs. $100 \pm 15 ; F=394.889 ; p<0.001)$ and significantly correlates with age (Table 2), although with a value very close to zero $(r=0.078 ; p<0.001)$.

TABLE 2 | Means and standard deviation of all parameters of the KTK (RS, MQ, WB raw, WB, MS raw, MS, JS raw, JS, HH raw, and HH) and their "Spearman rank order correlation" with age.

\begin{tabular}{|c|c|c|c|c|c|c|c|c|c|c|c|}
\hline & & MQ & RS & WB raw & WB & JS raw & JS & MS raw & MS & HH raw & $\mathrm{HH}$ \\
\hline & Means (sd) & 86.64 & 170.35 & 38.64 & 88.33 & 53.87 & 99.28 & 34.02 & 80.68 & 43.81 & 90.76 \\
\hline & & $(16.22)$ & $(49.83)$ & (16.92) & $(17.27)$ & (17.40) & $(18.27)$ & $(8.85)$ & (18.90) & (20.83) & (20.89) \\
\hline \multirow[t]{2}{*}{ Age } & Correlation coefficient $(r)$ & -0.148 & 0.678 & 0.459 & 0.078 & 0.674 & 0.006 & 0.298 & -0.331 & 0.545 & -0.103 \\
\hline & $p$ & $<0.001$ & $<0.001$ & $<0.001$ & $<0.001$ & $<0.001$ & n.s & $<0.001$ & $<0.001$ & $<0.001$ & $<0.001$ \\
\hline
\end{tabular}


TABLE 3 | Raw score (mean \pm standard deviation) of the four KTK subtests (walking backwards, moving sideways, jumping sideways, and hopping for height) for gender and age.

\begin{tabular}{|c|c|c|c|c|c|c|c|c|c|c|c|}
\hline & 6 & 7 & 8 & 9 & 10 & 11 & 12 & 13 & Age & Gender & $\begin{array}{l}\text { Age } x \\
\text { gender }\end{array}$ \\
\hline \multicolumn{12}{|c|}{ Walking backwards raw score } \\
\hline Girls & $26.84(12.95)$ & $30.35(13.46)$ & 36.04 (15.78) & $41.28(16.46)$ & 44.15 (15.77) & $48.63(14.74)$ & $52.72(15.04)$ & 48.67 (15.71) & \multirow{3}{*}{$\begin{array}{c}F=89.465 \\
p<0.001\end{array}$} & \multirow{3}{*}{$\begin{array}{l}F=14.52 \\
p<0.001\end{array}$} & \multirow{3}{*}{$\begin{array}{c}F=0.519 \\
p=\text { n.s. }\end{array}$} \\
\hline Boys & $25.65(12.76)$ & $28.20(15.88)$ & $31.99(15.15)$ & $37.79(14.37)$ & $40.69(15.44)$ & $45.53(14.05)$ & $48.99(15.24)$ & $49.29(14.67)$ & & & \\
\hline Total & $26.23(12.84)$ & $29.33(14.67)$ & $34.03(15.58)$ & $39.39(15.43)$ & $42.35(15.67)$ & $46.91(14.41)$ & $50.68(15.23)$ & $49.04(15.05)$ & & & \\
\hline \multicolumn{12}{|c|}{ Jumping sideways raw score } \\
\hline Girls & $31.54(10.22)$ & $40.96(12.94)$ & $46.56(13.27)$ & $52.77(13.03)$ & $58.17(12.27)$ & $63.22(12.13)$ & $67.63(11.37)$ & 71.87 (12.61) & \multirow{3}{*}{$\begin{array}{c}F=266.349 \\
p<0.001\end{array}$} & \multirow{3}{*}{$\begin{array}{c}F=24.529 \\
p<0.001\end{array}$} & \multirow{3}{*}{$\begin{array}{c}F=0.487 \\
p=\text { n.s. }\end{array}$} \\
\hline Boys & $34.09(11.70)$ & $42.90(11.70)$ & $50.22(12.60)$ & $56.31(13.50)$ & $59.86(13.66)$ & $66.40(13.38)$ & $72.16(14.06)$ & $73.65(13.56)$ & & & \\
\hline Total & $32.85(11.05)$ & $41.88(12.39)$ & $43.38(13.06)$ & $54.69(13.38)$ & $59.05(13.02)$ & $64.99(12.91)$ & $70.10(13.08)$ & $72.92(13.16)$ & & & \\
\hline \multicolumn{12}{|c|}{ Moving sideways raw score } \\
\hline Girls & $25.70(5.89)$ & $31.07(7.17)$ & $33.71(6.97)$ & $34.14(7.46)$ & $35.91(7.47)$ & $34.49(7.45)$ & 36.46 (10.05) & $37.17(10.10)$ & \multirow{3}{*}{$\begin{array}{l}F=50.91 \\
p<0.001\end{array}$} & \multirow{3}{*}{$\begin{array}{c}F=9.052 \\
p<0.01\end{array}$} & \multirow{3}{*}{$\begin{array}{c}F=0.97 \\
p=\text { n.s. }\end{array}$} \\
\hline Boys & $26.64(7.30)$ & $31.46(7.64)$ & $35.16(7.77)$ & $36.35(8.24)$ & $36.35(7.76)$ & $36.08(9.22)$ & $35.77(10.64)$ & $39.80(12.72)$ & & & \\
\hline Total & $26.18(6.65)$ & $31.26(7.39)$ & $34.43(7.40)$ & $35.34(7.96)$ & $36.14(7.61)$ & $35.38(8.50)$ & $36.09(10.36)$ & $38.73(11.76)$ & & & \\
\hline \multicolumn{12}{|c|}{ Hopping for height raw score } \\
\hline Girls & $21.63(11.04)$ & $30.85(15.30)$ & $33.88(16.39)$ & $44.87(20.29)$ & $51.23(19.48)$ & $57.06(17.50)$ & $54.04(15.49)$ & $58.31(15.46)$ & \multirow{3}{*}{$\begin{array}{c}F=136.186 \\
p<0.001\end{array}$} & \multirow{3}{*}{$\begin{array}{c}F=11.105 \\
p<0.001\end{array}$} & \multirow{3}{*}{$\begin{array}{c}F=0.903 \\
p=\text { n.s. }\end{array}$} \\
\hline Boys & $25.68(11.70)$ & $36.40(14.68)$ & $36.23(18.84)$ & $46.83(21.20)$ & $50.73(20.57)$ & $58.68(17.64)$ & $55.59(15.48)$ & $62.57(14.60)$ & & & \\
\hline Total & $23.71(11.54)$ & 33.49 (15.24) & 35.05 (17.67) & $45.94(20.79)$ & $50.97(20.03)$ & $57.96(17.56)$ & 54.89 (15.47) & $60.84(15.04)$ & & & \\
\hline
\end{tabular}

TABLE 4 | Standardized values (mean \pm standard deviation) of the four KTK subtests (walking backwards, moving sideways, jumping sideways, and hopping for height) for gender and age.

\begin{tabular}{|c|c|c|c|c|c|c|c|c|c|c|c|}
\hline & 6 & 7 & 8 & 9 & 10 & 11 & 12 & 13 & Age & Gender & Age $\times$ gender \\
\hline \multicolumn{12}{|c|}{$\begin{array}{l}\text { Walking backwards } \\
\text { (WB) }\end{array}$} \\
\hline Girls & $91.10(14.88)$ & $87.93(14.87)$ & $87.33(17.21)$ & $88.99(17.47)$ & 89.95 (16.94) & $93.23(17.19)$ & $96.10(19.94)$ & $87.70(21.31)$ & \multirow{3}{*}{$\begin{array}{l}F=6.683 \\
p<0.001\end{array}$} & \multirow{3}{*}{$\begin{array}{c}F=14.695 \\
p<0.001\end{array}$} & \multirow{3}{*}{$\begin{array}{c}F=0.592 \\
p=\text { n.s. }\end{array}$} \\
\hline Boys & 89.68 (14.64) & 85.50 (17.55) & 82.94 (16.54) & 85.41 (15.32) & 86.25 (16.45) & 89.51 (16.54) & $90.66(20.84)$ & $88.63(19.87)$ & & & \\
\hline Total & 90.37 (14.74) & 86.78 (16.22) & $85.15(17.00)$ & $87.05(16.41)$ & $87.98(16.76)$ & $91.16(16.90)$ & $93.13(20.57)$ & 88.26 (20.39) & & & \\
\hline \multicolumn{12}{|c|}{ Jumping sideways } \\
\hline \multicolumn{12}{|l|}{ (JS) } \\
\hline Girls & 90.92 (15.85) & 96.66 (18.80) & 98.02 (17.02) & 88.60 (18.85) & $89.85(16.70)$ & 95.12 (15.63) & 92.55 (17.62) & 90.54 (15.16) & \multirow{3}{*}{$\begin{array}{l}F=6.638 \\
p<0.001\end{array}$} & \multirow{3}{*}{$\begin{array}{c}F=257.363 \\
p<0.001\end{array}$} & \multirow{3}{*}{$\begin{aligned} F & =2.944 p \\
& <0.01\end{aligned}$} \\
\hline Boys & $102.00(16.09)$ & $108.26(15.61)$ & $105.76(16.31)$ & $106.80(16.05)$ & $101.15(17.62)$ & $104.94(17.28)$ & 106.01 (18.72) & $106.28(18.14)$ & & & \\
\hline Total & 96.61 (16.88) & $102.18(18.27)$ & $101.87(17.09)$ & 98.49 (19.59) & $95.71(18.07)$ & $100.58(17.24)$ & 99.89 (19.39) & 99.89 (18.62) & & & \\
\hline \multicolumn{12}{|c|}{ Moving sideways } \\
\hline \multicolumn{12}{|l|}{ (MS) } \\
\hline Girls & 84.27 (13.58) & $88.76(16.67)$ & 85.80 (16.54) & $79.93(15.42)$ & $76.63(13.85)$ & 71.66 (15.73) & $68.60(20.42)$ & $67.48(21.69)$ & \multirow{3}{*}{$\begin{array}{c}F=50.374 \\
p<0.001\end{array}$} & \multirow{3}{*}{$\begin{array}{c}F=11.876 \\
p<0.001\end{array}$} & \multirow{3}{*}{$\begin{array}{c}F=1.052 \\
p^{\prime}=\text { n.s. }\end{array}$} \\
\hline Boys & 86.64 (16.66) & $89.71(17.42)$ & 89.33 (18.57) & $84.83(17.14)$ & $77.89(14.97)$ & 75.28 (19.68) & $67.33(21.54)$ & $73.97(26.81)$ & & & \\
\hline Total & 85.49 (15.25) & $89.21(17.01)$ & $87.55(17.64)$ & 82.59 (16.54) & 77.28 (14.44) & 73.67 (18.08) & $67.90(21.00)$ & 71.34 (24.98) & & & \\
\hline \multicolumn{12}{|c|}{ Hopping for height } \\
\hline \multicolumn{12}{|l|}{ (HH) } \\
\hline Girls & 81.71 (15.74) & $91.70(19.48)$ & 90.00 (18.85) & $89.59(21.09)$ & 89.21 (22.42) & 93.34 (19.64) & 75.94 (22.90) & 77.26 (25.43) & \multirow{3}{*}{$\begin{array}{c}F=16.729 \\
p<0.001\end{array}$} & \multirow{3}{*}{$\begin{array}{l}F=66.92 \\
p<0.001\end{array}$} & \multirow{3}{*}{$\begin{array}{l}F=7.048 \\
p<0.001\end{array}$} \\
\hline Boys & $102.02(12.36)$ & $102.11(16.29)$ & $90.47(20.08)$ & 94.40 (20.71) & 92.29 (20.51) & $95.38(21.14)$ & 86.20 (19.72) & $84.99(24.20)$ & & & \\
\hline Total & $92.15(17.37)$ & 96.65 (18.74) & $90.23(19.45)$ & 92.20 (20.99) & $90.81(21.48)$ & $94.48(20.47)$ & $81.54(21.79)$ & 81.85 (24.91) & & & \\
\hline
\end{tabular}


In the other three subtests, boys performed better than girls (JS: $F=24.529 ; p<0.001-\mathrm{MS}: \quad F=9.052$; $p<0.01-\mathrm{HH}: F=11.105 ; p<0.001)$.

JS raw increased steadily with age $(r=0.674 ; p<0.001)$, and significant differences between all age pairs were found except 12 vs. 13 years (Figure 1B). The standardized mean value of JS is no different from the reference (respectively, $99.28 \pm 18.27$ vs. 100 $\pm 15 ; F=1.387 ; p=$ n.s.) and not related to age (Table 2 ).

MS raw grow up to 8 years (6 vs. 7 years: $p<0.001 ; 7$ vs. 8 years: $p<0.001)$; between 8 and 12 years, it does not show significant differences and, finally, at 13 years is greater than all the others except for 10 and 12 years (Figure 1C). The standardized mean value of MS is lower than the reference (respectively, $80.68 \pm 18.90$ vs. $100 \pm 15 ; F=950.028 ; p<0.001$ ) and decreases with age $(r=-0.331 ; p<0.001)$.

$\mathrm{HH}$ raw grow regularly with age $(r=0.545 ; p<0.001)$. Significant differences were found between all age couples except for 7 vs. 8 years, 10 vs. 12 years, 11 vs. 12 years, 11 vs. 13 years, and 12 vs. 13 years (Figure 1D). The standardized mean value of $\mathrm{HH}$ is lower than the reference (respectively, $90.76 \pm$ 20.89 vs. $100 \pm 15 ; F=186.665 ; p<0.001)$ and decreases with age $(r=-0.103 ; p<0.001)$.

\section{DISCUSSION}

The main goal of our cross-sectional research was to verify, for the first time, the current values of GMC of Italian boys and girls between 6 and 13 years of age, based on a large cohort of Italian children living in the north, center, and south of Italy. It was assumed that the current coordination levels of Italian boys and girls are lower than the reference values of the KTK battery. Secondary goals were to study gender differences, and the four subtests trend with ages. In all four subtests, we assume an increase in raw values that slowed down with increasing age. We expected that girls exhibit similar or higher values than boys in the WB. In the JS and $\mathrm{HH}$, boys should show overall values higher than girls due to higher strength levels. There are no known reasons to assume gender difference in MS. Our cross-sectional search has applied the KTK test battery to a large population between 6 and 13 years. Globally, GMC values of Italian youth were lower than reference (46). Boys showed better performance than girls in MQ, RS as well as in three on four subtests.

The relevant number of studies that adopted KTK permitted us to compare our overall results (RS and MQ) not only with 1974 references (46) but also with similar researches conducted by Vandorpe et al. (45) and Moreira et al. (58). To interpret MQ values, we were able to consider the Vandorpe et al. (45) and Kiphard and Schilling $(46,47)$ results but not those of Moreira that did not calculate this parameter (Tables 5, 6). To compare RS and the four subtests among the four searches (Table 7), subjects between 6 and 10 years old, common to the four studies, were considered $(45-47,58)$. Despite this limitation, mandatory because Brazilian data were collected only for this age group, it was thought appropriate to consider Moreira data, gathered in a very different sociocultural reality but almost simultaneously with the Italian data. We compared, therefore, our data both on a worldwide geographical scale and on a time scale of about 45 years. The Kiphard 1974 German survey collected the original MQ data and was carried out on a population aged 5 to 14 years old. The Vandorpe Belgian survey investigated, in 2011, a population aged 6 to 11 years (45) while Moreira published her data from Brazilian children from 6 to 10 years old, in 2019.

Regarding MQ, significant differences between the three studies $(F=385.832 ; p<0.001)$ were found. Both Belgian and Italian results were lower than the German references (Belgium $=-3.5 \%$; Italy $=-13.36 \%$; $p<0.001)$. The Italian values were significantly lower than Belgium ones $(-10.22 \%$; $p<0.001)$. This result seems to indicate a constant GMC reduction over time. Table 6 describes, for the Italian search, the numbers and percentages of participants included in the MQ five levels. For the Belgian and German searches, the table reports only the participants' percentages at every level. The chi-square shows a significant difference in the distributions of subjects $\left[\mathrm{X}^{2}(8, N=\right.$ $5,904)=654.050, p<0.001]$ with Italian "Bad" and "Low" groups much more numerous than others.

Table 7 presents the raw values of the four subtests and RS, obtained from the four studies, with significant differences among groups $(F=3,332.086 ; p<0.001)$. The German's RS values are higher than Belgian ones (Germany 193.28 \pm 10.07 ; Belgium $=175.28 \pm 10.37 ; p \leq 0.001)$ while Italian data, lower than the first two $(p<0.001)$, are slightly higher than the Brazilian ones (Italy $154.77 \pm 10.07$; Brazil $=152.05 \pm 7.24$; $p \leq 0.001)$. Comparison among these four searches seems to confirm a downward trend in GMC and its characterization by geographical and sociocultural areas $(14,63)$. RS shows an increase with age that, however, tends to decrease from 11 years onward. Similar trends were shown in the original German KTK data, whereas Vandorpe et al. (45) measured a substantially linear increase. Vaccari et al. (64) identified, in young Italians of the same age, a trend with a gradual slowing increase in performance with age also in measures of balance, cardiorespiratory fitness, and lower extremity power.

A secondary goal was to study the four subtest trends in the different ages and the two genders. Our study showed Italian results below the German and Belgian values for all raw values of the four subtests $(p<0.001)$. In comparison with the Brazilian data, the Italian WB and JS subtests were better (WB: Italy = $35.06 \pm 7.02$; Brazil $=34.09 \pm 6.01 ; p<0.01$; JS: Italy $=47.51 \pm$ 9.85; Brazil $=40.01 \pm 7.72 ; p<0.001)$, while it was the opposite for MS and $\mathrm{HH}$ (MS: Italy = 33.18 \pm 4.37 ; Brazil = $35.57 \pm 5.52$; $p<0.001 ; \mathrm{HH}$ : Italy $=39.01 \pm 10.31 ;$ Brazil $=42.38 \pm 7.53 ; p<$ $0.001)$. Overall, the Italian standardized mean values of three out of four subtests were well below the German references (WB = $-11.68 \%$; MS $=-19.32 \% ; \mathrm{HH}=-9.24 \% ; p<0.001)$. Only for JS were the Italian values similar (JS $=99.28 ; p=$ n.s.).

Our results showed better performance in boys than girls in the raw scores of three of the four subtests (JS: $F=24.529$; MS: $F=9.052$; HH: $F=11.105)$, while girls had better performances than boys in the WB $(F=14.52)$.

Overall, the four subtests showed results that do not match those that emerged from the three other searches that we adopted as a comparison. The only univocal result in all searches regarded $\mathrm{HH}$, which showed higher levels of boys than those of girls. In 

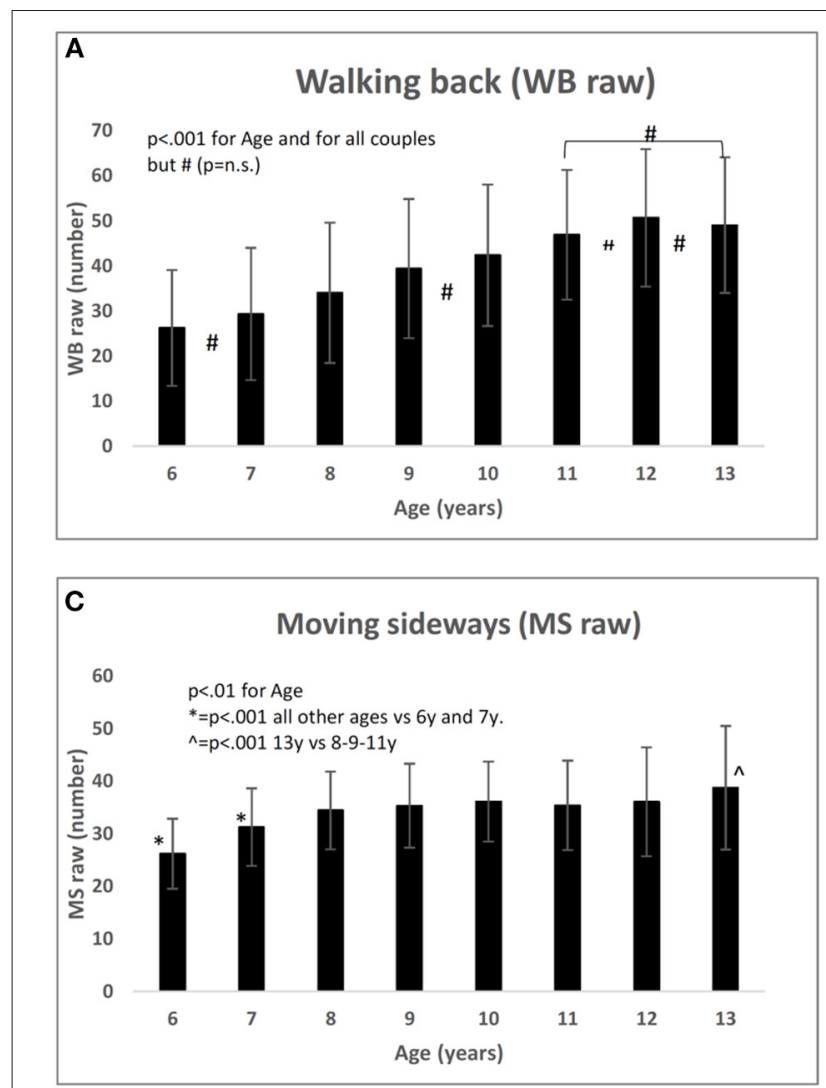
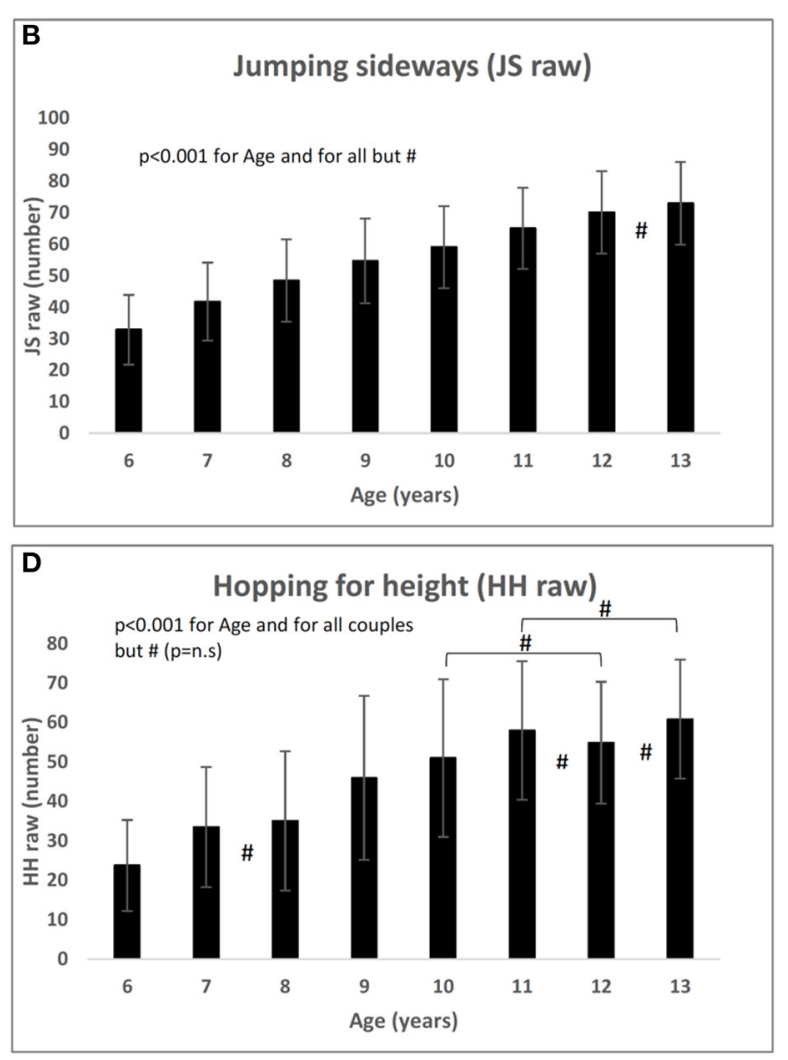

FIGURE 1 | Raw values of the four subsets between 6 and 13 years. (A) Walking Back (WB raw); (B) Jumping Sideways; (C) Moving Sideways; (D) Hopping for Height.

TABLE 5 | The number of subjects, means, standard deviations, and differences (percentages) of the motor quotient (MQ) in three comparable searches: Kiphard (46), Germany; Vandorpe et al. (45), Belgium; and our research, Italy, 2021.

\begin{tabular}{|c|c|c|c|c|}
\hline Motor quotient (MQ) & Number of subjects & Mean & St. dev. & $\Delta \%$ vs. Germany \\
\hline Germany 1974 & 1,228 & $100^{* \wedge}$ & 15 & - \\
\hline Belgium 2011 & 2,470 & $96.5^{\wedge}$ & 14.3 & -3.5 \\
\hline Italy 2021 & 2,206 & 86.64 & 16.22 & -13.36 \\
\hline
\end{tabular}

${ }^{*} p<0.001$ vs. Belgium, ^ $p<0.001$ vs. Italy.

$\mathrm{WB}$, the best results of the girls were detected by our research and by Vandorpe; the German and Brazilian data, instead, showed no differences. In JS, the Italian data documented, like the German ones, better values of girls than of boys, while the Belgians and Brazilians have not found any differences. In MS, our data were the only ones to show a prevalence of the boys' performances.

For the $\mathrm{HH}$ test, it seems reasonable to attribute to the greater power developed by boys the cause of their better results in all searches $(45,65)$. The heterogeneity of the results of the other three subtests (MB, JS, and MS) suggests that the main factors potentially correlated with coordinative performance, such as the amount of PA, different types of sports practices, and body composition, but also less investigated factors such as sedentariness, sociocultural vulnerability conditions, and natural and urban environment, which act differently for girls and boys. We can, in this regard, consider a limitation of our research not having considered the many correlates and determinants of GMC. We consider, instead, a strong point of our work, the size of the population investigated in a nation, Italy, which did not have such extensive data in this field. Another element that seems relevant is the confrontation of our results with those of other searches that have used the KTK, carried out in different geographical areas and in a time ranging from 1974 to the present.

The overall picture of the results we have presented, first of all, makes us consider the continuing decline in GMC as worrying: the negative effects on health and lifestyles could weigh heavily on current generations. The significant differences between genders make us believe it appropriate to maintain a differentiated normalization. As was expected, RS increased with age, and it seems reasonable, therefore, to maintain an age-based normalization of the GMC. On the 
TABLE 6 | Distribution of subjects in the five levels of motor quotient (MQ level) of three comparable searches.

\begin{tabular}{|c|c|c|c|c|}
\hline $\begin{array}{l}\text { Distribution in } \\
\text { "MQ levels" }\end{array}$ & Italy 2020 (number) & Italy 2020 (\%) & Belgium 2008 (\%) & Germany 1974 (\%) \\
\hline Bad & 368 & 16.7 & 4.3 & 2 \\
\hline Normal & 1,110 & 50.3 & 70.2 & 68 \\
\hline Good & 72 & 3.3 & 8.3 & 14 \\
\hline
\end{tabular}

MQ level based on MQ values: bad (56-70 MQ); low (71-85 MQ); normal (86-115 MQ); good (116-130 MQ); excellent (131-145 MQ).

TABLE 7 | Values of RS, WB raw, JS raw, Ms raw, and HH raw, in subjects from 6 to 10 years old.

\begin{tabular}{|c|c|c|c|c|c|}
\hline & Mean & Number & $\begin{array}{l}\text { Standard } \\
\text { deviation }\end{array}$ & $\begin{array}{l}\text { Between } \\
\text { groups }\end{array}$ & Percentage difference vs. Germany 1974 \\
\hline \multicolumn{6}{|l|}{ Walking back } \\
\hline \multicolumn{6}{|l|}{ (WB raw) } \\
\hline Germany 1974 & $49,477^{\star} \wedge \circ$ & 677 & 8,121 & \multirow{4}{*}{$\begin{array}{c}F=733.35 \\
p<0.001\end{array}$} & - \\
\hline Belgium 2011 & $37,632^{\wedge} \circ$ & 2,115 & 7,181 & & $-23.94 \%$ \\
\hline Brazil 2019 & 34,086 & 566 & 6,008 & & $-31.11 \%$ \\
\hline Italy 2021 & $35,059^{\#}$ & 1,631 & 7,020 & & -29.14 \\
\hline \multicolumn{6}{|c|}{ Jumping sideways } \\
\hline \multicolumn{6}{|c|}{ (JS raw) } \\
\hline Germany 1974 & $52,408^{\wedge \circ}$ & 677 & 10,734 & \multirow{4}{*}{$\begin{array}{c}F=268.513 \\
p<0.001\end{array}$} & - \\
\hline Belgium 2011 & $52,147^{\wedge \circ}$ & 2,115 & 9,999 & & n.s. \\
\hline Brazil 2019 & 40,011 & 566 & 7,719 & & -23.65 \\
\hline Italy 2021 & $47,515 \wedge$ & 1,631 & 9,846 & & -9.34 \\
\hline \multicolumn{6}{|c|}{ Moving sideways } \\
\hline \multicolumn{6}{|l|}{ (MS raw) } \\
\hline Germany 1974 & $41,911^{\star} \wedge \circ$ & 677 & 5,655 & \multirow{4}{*}{$\begin{array}{c}F=527.406 \\
p<0.001\end{array}$} & - \\
\hline Belgium 2011 & $36,848^{\wedge \circ}$ & 2,115 & 4,859 & & -12.08 \\
\hline Brazil 2019 & $35,569^{\circ}$ & 566 & 5,519 & & -15.13 \\
\hline Italy 2021 & 33,183 & 1,631 & 4,368 & & -20.83 \\
\hline \multicolumn{6}{|c|}{ Hopping for height } \\
\hline \multicolumn{6}{|l|}{ (HH raw) } \\
\hline Germany 1974 & $49,479^{\wedge} \circ$ & 677 & 11,542 & \multirow{4}{*}{$\begin{array}{c}F=344.367 \\
p<0.001\end{array}$} & - \\
\hline Belgium 2011 & $48,651^{\wedge \circ}$ & 2,115 & 9,891 & & n.s. \\
\hline Brazil 2019 & $42,383^{\circ}$ & 566 & 7,535 & & -14.34 \\
\hline \multirow[t]{2}{*}{ Italy 2021} & 39,014 & 1,631 & 10,306 & & -21.15 \\
\hline & Sum of means & Number & $\begin{array}{l}\text { Standard } \\
\text { deviation }\end{array}$ & $\begin{array}{l}\text { Between } \\
\text { groups }\end{array}$ & Percentage difference vs. Germany 1974 \\
\hline \multicolumn{6}{|l|}{ Raw score } \\
\hline \multicolumn{6}{|l|}{ (RS) } \\
\hline Germany 1974 & $193,275^{\star \wedge}$ & 677 & 10,070 & \multirow{4}{*}{$\begin{array}{c}F=3,332,086 \\
p<0.001\end{array}$} & - \\
\hline Belgium 2011 & $175,278^{\wedge} \circ$ & 2,115 & 10,365 & & $-9.31 \%$ \\
\hline Brazil 2019 & 152,048 & 566 & 7,238 & & $-21.33 \%$ \\
\hline Italy 2021 & $154,771 \wedge$ & 1,631 & 9,911 & & $-19.92 \%$ \\
\hline
\end{tabular}

${ }^{*} p<0.001$ vs. Belgium, ${ }^{\wedge} p<0.001$ vs. Brazil, ${ }^{\circ} p<0.001$ vs. Italy, ${ }^{\#} p<0.01$ vs. Brazil.

Data elaborated from Kiphard (46) (Germany); Vandorpe et al. (45) (Belgium); Moreira et al. (58) (Brazil) and from our present research (Italy).

contrary, MQ tended to decrease, confirming the observations of Giuriato et al. (55). It seems that today's young people accumulate less significant motor experiences over the years, from both a quantitative (66) and qualitative (1) point of view, compared to those achieved by their peers in the 1970s. This vicious circle favors an increase in weight and fat mass that is not proportionate to the increase in height (67). However, the possibility of a reverse dynamic must also 
be considered, with overweight acting as a trigger to reduce PA (11).

It seems reasonable to argue, therefore, that greater use of GMC measures is useful to favor their better solicitation both in physical education and in youth sports training. It is believed that an improvement in GMC's parameters is achievable by improving both the structured physical activities and the spontaneous lifestyle of children and adolescents.

This implies a greater awareness of the reduction of this physical capacity by teachers, coaches, and policymakers. The first two will thus be able to adopt proposals for more appropriate physical activities while the latter will have a more updated and complete picture of the development needs of young people.

\section{PERSPECTIVE}

The availability of updated assessments of GMC will help physical education in schools, youth sports training, and the orientation of PA promotion policies. We believe that the KTK standards proposed by Kiphard and Schilling in 1974 (46) no longer correctly represent the benchmarks for GMC. It remains, in any case, the need to provide targets for improvement of today's results which show a wide reduction. We think, therefore, that the integration of recent results with data from the original search and the more recent past could provide new standards based on a wider population, achieving both the representativeness of different situations and the stimulus for the improvement of current coordination skills. Also, in light of the reduction of the results currently obtained by subjects up to 14 years, it seems reasonable to verify the applicability of the KTK test battery in subjects older than 14 years. If KTK were applicable in youth over 14 years, it could provide useful references to sustain policies that promote PA, sport, and physical education throughout the youth.

\section{REFERENCES}

1. Barnett LM, Lai SK, Veldman SLC, Hardy LL, Cliff DP, Morgan PJ, et al. Correlates of gross motor competence in children and adolescents: a systematic review and meta-analysis. Sports Med. (2016) 46:166388. doi: 10.1007/s40279-016-0495-z

2. Gallahue D, Ozmun J. Understanding Motor Development: Infants, Children, Adolescents, Adults. 7th ed. Boston: McGraw-Hill (2011).

3. Coppens E, Laureys F, Mostaert M, D’Hondt E, Deconinck FJA, Lenoir M. Validation of a motor competence assessment tool for children and adolescents $(\mathrm{KTK} 3+)$ with normative values for 6- to 19-year-olds. Front Physiol. (2021) 12:652952. doi: 10.3389/fphys.2021.652952

4. Barnett LM, Van Beurden E, Morgan PJ, Brooks LO, Beard JR. Childhood motor skill proficiency as a predictor of adolescent physical activity. J Adolesc Health. (2009) 44:252-9. doi: 10.1016/j.jadohealth.2008.07.004

5. Lloyd RS, Cronin JB, Faigenbaum AD, Haff GG, Howard R, Kraemer WJ, et al. National strength and conditioning association position statement on long-term athletic development. J Strength Cond Res. (2016) 30:1491509. doi: 10.1519/JSC.0000000000001387

6. Robinson LE, Stodden DF, Barnett LM, Lopes VP, Logan SW, Rodrigues LP, et al. Motor competence and its effect on positive developmental trajectories of health. Sports Med. (2015) 45:1273-84. doi: 10.1007/s40279-015-0351-6

7. Fransen J, Pion J, Vandendriessche J, Vandorpe B, Vaeyens R, Lenoir M, Philippaerts RM. Differences in physical fitness and gross motor coordination
Finally, we believe that further longitudinal research should verify the actual development of GMC with age.

\section{DATA AVAILABILITY STATEMENT}

The raw data supporting the conclusions of this article will be made available by the authors, without undue reservation.

\section{ETHICS STATEMENT}

The studies involving human participants were reviewed and approved by Ethical Boards of the Universities of Verona (N. 2019-UNVRCLE-0298910) and Palermo (N. 8/2019) as well as the Institutional Review Board of the University of Rome Foro Italico. Written informed consent to participate in this study was provided by the participants' legal guardian/next of kin.

\section{AUTHOR CONTRIBUTIONS}

ML, MB, MCG, MG, VB, and FS conceptualization and methodology. MG, VB, MCG, and GB data collection. ML and $\mathrm{MG}$ data analysis. ML, MG, FS, MB, LG, and CB data interpretation. ML, MG, and VB writing-original draft preparation. MG, VB, and GB writing-review and editing. LG, $\mathrm{AP}, \mathrm{CB}$, and FS supervision. All authors have read and approved the final version of the manuscript and agree with the order of presentation of the authors.

\section{ACKNOWLEDGMENTS}

The authors are very grateful to schoolteachers and university students for their collaboration in the collecting data and to schools and children participating in the study. in boys aged 6-12 years specializing in one versus sampling more than one sport. J Sports Sci. (2012) 30:379-86. doi: 10.1080/02640414.2011.6 42808

8. Vandorpe B, Vandendriessche J, Vaeyens R, Pion J, Matthys S, Lefevre J, et al. Relationship between sports participation and the level of motor coordination in childhood: a longitudinal approach. J Sci Med Sport. (2012) 15:220-5. doi: 10.1016/j.jsams.2011.09.006

9. Pesce C, Ben-Soussan TD. Chapter 12 - "Cogito ergo sum” or "ambulo ergo sum"? New perspectives in developmental exercise and cognition research. In: McMorris T, editor. Exercise-Cognition Interaction. Academic Press (2016). p. 251-82.

10. Faigenbaum AD, Myer GD. Exercise deficit disorder in youth. Curr Sports Med Rep. (2012) 11:196-200. doi: 10.1249/JSR.0b013e31825da961

11. Stodden D, Goodway JD, Langendorfer SL, Robertson MA, Rudisill M, Garcia C. A developmental perspective on the role of motor skill competence in physical activity: an emergent relationship. Quest. (2008) 60:290306. doi: 10.1080/00336297.2008.10483582

12. D'Hondt E, Deforche B, Vaeyens R, Vandorpe B, Vandendriessche J, Pion J, et al. Gross motor coordination in relation to weight status and age in 5- to 12-year-old boys and girls: a cross-sectional study. Int J Pediatr Obes. (2011) 6:e556-64. doi: 10.3109/17477166.2010.500388

13. Reinert KR, Po'e EK, Barkin SL. The relationship between executive function and obesity in children and adolescents: a systematic literature review. J Obes. (2013) 2013:820956. doi: 10.1155/2013/820956 
14. Bardid F, Rudd JR, Lenoir M, Polman R, Barnett LM. Crosscultural comparison of motor competence in children from Australia and Belgium. Front Psychol. (2015) 6:964. doi: 10.3389/fpsyg.2015. 00964

15. D'Hondt E, Deforche B, Gentier I, Verstuyf J, Vaeyens R, et al. A longitudinal study of gross motor coordination and weight status in children. Obesity (Silver Spring). (2014) 22:1505-11. doi: 10.1002/oby.20723

16. Lopes VP, Malina RM, Maia JAR, Rodrigues LP. Body mass index and motor coordination: non-linear relationships in children 6-10 years. Child Care Health Dev. (2018) 44:443-51. doi: 10.1111/cch.12557

17. Lopes VP, Stodden DF, Bianchi MM, Maia JA, Rodrigues LP. Correlation between BMI and motor coordination in children. J Sci Med Sport. (2012) 15:38-43. doi: 10.1016/j.jsams.2011.07.005

18. Fransen J, D’Hondt E, Bourgois J, Vaeyens R, Philippaerts RM, Lenoir M. Motor competence assessment in children: convergent and discriminant validity between the BOT-2 Short Form and KTK testing batteries. Res Dev Disabil. (2014) 35:1375-83. doi: 10.1016/j.ridd.2014.03.011

19. Cattuzzo MT, dos Santos Henrique R, Re' AHN, de Oliveira IS, Melo BM, de Sousa Moura M, et al. Motor competence and health related physical fitness in youth: a systematic review. J Sci Med Sport. (2016) 19:1239. doi: 10.1016/j.jsams.2014.12.004

20. Strong WB, Malina RM, Blimkie CJR, Daniels SR, Dishman RK, Gutin B, et al. Evidence based physical activity for school-age youth. J Pediatr. (2005) 146:732-7. doi: 10.1016/j.jpeds.2005.01.055

21. Stodden DF, Goodway JD. The dynamic association between motor skill development and physical activity. J Phys Educ Recreat Dance. (2007) 78:3349. doi: 10.1080/07303084.2007.10598077

22. Gao Z, Wang R. Children's motor skill competence, physical activity, fitness, andhealthpromotion. J Sport Health Sci. (2019) 8:95-7. doi: 10.1016/j.jshs.2018.12.002

23. Cairney J, Dudley D, Kwan M, Bulten R, Kriellaars D. Physical literacy, physical activity and health: toward an evidence-informed conceptual model. Sports Med. (2019) 49:371-83. doi: 10.1007/s40279-019-01063-3

24. Lubans DR, Morgan PJ, Cliff DP, Barnett LM, Okely AD. Fundamental movement skills in children and adolescents. Sports Med. (2010) 40:101935. doi: 10.2165/11536850-000000000-00000

25. Riethmuller AM, Jones R, Okely AD. Efficacy of interventions to improve motor development in young children: a systematic review. Pediatrics. (2009) 124:e782-92. doi: 10.1542/peds.2009-0333

26. Lopes VP, Rodrigues LP, Maia JAR, Malina RM. Motor coordination as predictor of physical activity in childhood. Scand J Med Sci Sports. (2011) 21:663-9. doi: 10.1111/j.1600-0838.2009.01027.x

27. Hardy LL, Barnett L, Espinel P, Okely AD. Thirteen-year trends in child and adolescent fundamental movement skills: 1997-2010. Med Sci Sports Exerc. (2013) 45:1965-70. doi: 10.1249/MSS.0b013e318295a9fc

28. D'Hondt E, Deforche B, Gentier I, De Bourdeaudhuij I, Vaeyens R, Philippaerts R, et al. A longitudinal analysis of gross motor coordination in overweight and obese children versus normal-weight peers. Int J Obes (Lond). (2013) 37:61-7. doi: 10.1038/ijo.2012.55

29. Diamond A. Close interrelation of motor development and cognitive development and of the cerebellum and prefrontal cortex. Child Dev. (2000) 71:44-56. doi: 10.1111/1467-8624.00117

30. Diamond A, Ling DS. Conclusions about interventions, programs, and approaches for improving executive functions that appear justified and those that, despite much hype, do not. Dev Cogn Neurosci. (2016) 18:3448. doi: 10.1016/j.dcn.2015.11.005

31. Pangelinan MM, Zhang G, VanMeter JW, Clark JE, Hatfield BD, Haufler AJ. Beyond age and gender: relationships between cortical and subcortical brain volume and cognitive-motor abilities in school-age children. Neuroimage. (2011) 54:3093-100. doi: 10.1016/j.neuroimage.2010.11.021

32. Roebers CM, Röthlisberger M, Neuenschwander R, Cimeli P, Michel E, Jäger $\mathrm{K}$. The relation between cognitive and motor performance and their relevance for children's transition to school: a latent variable approach. Hum Mov Sci Feb. (2014) 33:284-97. doi: 10.1016/j.humov.2013.08.011

33. Rigoli D, Piek JP, Kane R, Oosterlaan J. An examination of the relationship between motor coordination and executive functions in adolescents. Dev Med Child Neurol. (2012) 54:1025-31. doi: 10.1111/j.1469-8749.2012.0 4403.x
34. Hillman $\mathrm{CH}$, Erickson KI, Kramer AF. Be smart, exercise your heart: exercise effects on brain and cognition. Nat Rev Neurosci. (2008) 9:5865. doi: $10.1038 / \mathrm{nrn} 2298$

35. Marchetti R, Forte R, Borzacchini M, Vazou S, Tomporowski PD, Pesce C. Physical and motor fitness, sport skills and executive function in adolescents: a moderated prediction model. Psychology. (2015) 6:191529. doi: 10.4236/psych.2015.614189

36. Cools W, Martelaer KD, Samaey C, Andries C. Movement skill assessment of typically developing preschool children: a review of seven movement skill assessment tools. J Sports Sci Med. (2009) 8:154-68.

37. Hands B, Licari M, Piek J. A review of five tests to identify motor coordination difficulties in young adults. Res Dev Disabil. (2015) 41-42:4051. doi: 10.1016/j.ridd.2015.05.009

38. Eddy LH, Bingham DD, Crossley KL, Shahid NF, Ellingham-Khan M, Otteslev A, et al. The validity and reliability of observational assessment tools available to measure fundamental movement skills in school-age children: a systematic review. PLoS ONE. (2020) 15:e0237919. doi: 10.1371/journal.pone.0237919

39. Cancer A, Minoliti R, Crepaldi M, Antonietti A. Identifying developmental motor difficulties: a review of tests to assess motor coordination in children. $J$ Funct Morphol Kinesiol. (2020) 5:16. doi: 10.3390/jfmk5010016

40. World Health Organization. Physical Activity Strategy for the WHO European Region 2016-2025. Regional Committee for Europe 65th Session. Vilnius: World Health Organization (2015).

41. World Health Organization. Global Action Plan on Physical Activity 20182030: More Active People for a Healthier World. Geneva: World Health Organization (2018).

42. Ministero della Salute. Linee di indirizzo sull'attività fisica per le differenti fasce d'età e con riferimento a situazioni fisiologiche e fisiopatologiche e a sottogruppi specifici di popolazione. Roma (2019).

43. Department of Health and Social Care. Physical Activity Guidelines: UK Chief Medical Officers' Report. Department of Health and Social Care; London, UK (2019). Available online at: https://www.gov.uk/government/publications/ physical-activity-guidelines-uk-chief-medical-officers-report (accessed April 9, 2021).

44. ESSA. Exercise for Kids. (2020). Available online at: https://exerciseright. com.au/wp-content/uploads/2020/05/ESSA_Kids-Exercise-eBook-2020.pdf (accessed September 15, 2021).

45. Vandorpe B, Vandendriessche J, Lefevre J, Pion J, Vaeyens R, Matthys S, et al. The KörperkoordinationsTest für Kinder: reference values and suitability for 6-12-year-old children in Flanders. Scand J Med Sci Sports. (2011) 21:37888. doi: 10.1111/j.1600-0838.2009.01067.x

46. Kiphard EJ, Schilling F. Körperkoordinationstest für Kinder. Weinheim: Beltz Test GmbH (1974).

47. Kiphard EJ, Schilling F. Korperkoordinationstest fur Kinder. 2nd ed. Weinheim: Beltz Test GmbH (2007).

48. Iivonen S, Sääkslahti A, Laukkanen A. A review of studies using the Körperkoordinationstest für Kinder (KTK). Eur J Adap Phys Activity. (2016) 8:18-36. doi: 10.5507/euj.2015.006

49. Bruininks RH, Bruininks BD. BOT 2 Bruininks-Oseretsky Test of Motor Proficiency. 2nd edn. Minneapolis, MN: AGS Publishing (2005).

50. O’Brien-Smith J, Tribolet R, Smith MR, Bennett KJM, Fransen J, Pion J, et al. The use of the Körperkoordinationstest für Kinder in the talent pathway in youth athletes: a systematic review. J Sci Med Sport. (2019) 22:10219. doi: 10.1016/j.jsams.2019.05.014

51. Morano M, Colella D, Caroli M. Gross motor skill performance in a sample of overweight and non - overweight preschool children. Int J Pediatr Obes. (2011) 6:42-6. doi: 10.3109/17477166.2011.613665

52. Morano M, Colella D, Rutigliano I, Fiore P, Pettoello-Mantovani M, Campanozzi A. A multi-modal training programme to improve physical activity, physical fitness and perceived physical ability in obese children. $J$ Sports Sci. (2014) 32:345-53. doi: 10.1080/02640414.2013.824602

53. Sgrò F, Quinto A, Messana L, Pignato S, Lipoma M. Assessment of gross motor developmental level in Italian primary school children. J Phys Educ Sport. (2017) 17:1954-59. doi: 10.7752/jpes.2017.03192

54. Schembri R, Quinto A, Aiello F, Pignato S, Sgrò F. The relationship between the practice of physical activity and sport and the level of motor competence in primary school children. J Phys Educ Sport. (2019) 19(Suppl. 5):19948. doi: 10.7752/jpes.2019.s5297 
55. Giuriato M, Pugliese L, Biino V, Bertinato L, La Torre A, Lovecchio N. Association between motor coordination, body mass index, and sports participation in children 6-11 years old. Sport Sci Health. (2019) 15:4638. doi: 10.1007/s11332-019-00554-0

56. Scordella A, Di Sano S, Aureli T, Cerratti P, Verratti V, Fanò-Illic G, Pietrangelo T. The role of general dynamic coordination in the handwriting skills of children. Front Psychol. (2015) 6:580. doi: 10.3389/fpsyg.2015.00580

57. Battaglia G, Alesi M, Tabacchi G, Palma A, Bellafiore M. The development of motor and pre-literacy skills by a physical education program in preschool children: a non-randomized pilot trial. Front Psychol. (2019) 9:2694. doi: 10.3389/fpsyg.2018.02694

58. Moreira JPA, Lopes MC, Miranda-Júnior MV, Valentini NC, Lage GM, Albuquerque MR. K.2019erque pilot trial F.2 Kinder (KTK) for Brazilian children and adolescents: factor analysis, invariance and factor score. Front Psychol. (2019) 10:2524. doi: 10.3389/fpsyg.2019. 02524

59. Clarys JP, Provyn S, Marfell-Jones M, Van Roy P. Morphological and constitutional comparison of age-matched in-vivo and post-mortem populations. Morphologie. (2006) 90:18996. doi: 10.1016/S1286-0115(06)74505-2

60. Cole TJ, Bellizzi MC, Flegal KM, Dietz WH. Establishing a standard definition for child overweight and obesity worldwide: international survey. BMJ. (2000) 320:1240-3 doi: 10.1136/bmj.320.7244.1240

61. Cole TJ, Flegal KM, Nicholls D, Jackson AA. Body mass index cut offs to define thinness in children and adolescents: international survey. BMJ. (2007) 335:194. doi: 10.1136/bmj.39238.399444.55

62. Nardone P, Spinelli A, Buoncristiano M, Lauria L, Pierannunzio D, Galeone D. Il Sistema di sorveglianza OKkio alla SALUTE: risultati 2016 [The Italian Surveillance system OKkio alla Salute: 2016 results]. Notiziario dell'Istituto Superiore di Sanità. (2018) 31(Suppl. 1):7-8.

63. Haga M, Tortella P, Asonitou K, Charitou S, Koutsouki D, Fumagalli $\mathrm{G}$, et al. Cross-Cultural Aspects: Exploring Motor Competence among
7- to 8-Year-Old Children From Greece, Italy, and Norway. SAGE Open (2018). doi: 10.1177/2158244018768381

64. Vaccari F, Fiori F, Bravo G, Parpinel M, Messina G, Malavolta R, et al. Physical fitness reference standards in Italian children. Eur J Pediatr. (2021) 180:1789-98. doi: 10.1007/s00431-021-03946-y

65. Prätorius B, Milani TL. Motor abilities of children: abilities of coordination balance: examination of differences between children of different social groups. Dtsch Z Sportmed. (2004) 55:172-6.

66. García-Hermoso A, Ramírez-Vélez R, Saavedra JM. Exercise, health outcomes, and pædiatric obesity: a systematic review of meta-analyses. J Sci Med Sport. (2019) 22:76-84. doi: 10.1016/j.jsams.2018.07.006

67. Cali AM, Caprio S. Obesity in children and adolescents. J Clin Endocrinol Metab. (2008) 93(Suppl. 1):S31-6. doi: 10.1210/jc.2008-1363

Conflict of Interest: The authors declare that the research was conducted in the absence of any commercial or financial relationships that could be construed as a potential conflict of interest.

Publisher's Note: All claims expressed in this article are solely those of the authors and do not necessarily represent those of their affiliated organizations, or those of the publisher, the editors and the reviewers. Any product that may be evaluated in this article, or claim that may be made by its manufacturer, is not guaranteed or endorsed by the publisher.

Copyright (C) 2021 Giuriato, Biino, Bellafiore, Battaglia, Palma, Baldari, Guidetti, Gallotta, Schena and Lanza. This is an open-access article distributed under the terms of the Creative Commons Attribution License (CC BY). The use, distribution or reproduction in other forums is permitted, provided the original author(s) and the copyright owner(s) are credited and that the original publication in this journal is cited, in accordance with accepted academic practice. No use, distribution or reproduction is permitted which does not comply with these terms. 